\title{
Lymphatic Vessel
}

National Cancer Institute

\section{Source}

National Cancer Institute. Lymphatic Vessel. NCI Thesaurus. Code C33038.

A tubule that carries lymph throughout the body. 